\title{
Circumferential treatment of long-segment Barrett's esophagus using the next-generation cryoballoon
}

A 71-year-old man was referred for ablation of a long segment of Barrett's esophagus, $6 \mathrm{~cm}$ in length, with confirmed multifocal low grade dysplasia. He was offered radiofrequency ablation (RFA) but declined this treatment as a family member had experienced extreme pain associated with RFA. Given cryotherapy is efficacious for Barrett's ablation [1] and is associated with less pain than RFA $[2,3]$, the patient was offered cryotherapy, which he accepted.

The patient was treated with the next generation of cryoballoon device with the new standard 90 balloon (C2 CryoBalIoon 90 ablation system; Pentax Medical, Redwood City, California, USA), which treats a large area $(3 \mathrm{~cm}$ long, and approximately a quarter of the esophageal circumference) ( $\triangleright$ Fig. 1, $>$ Video 1). The new cryoballoon ablation system is commercially available in the United States and is approved by the US Food and Drug Administration. The entire segment was treated with low dose cryogen $(0.9 \mathrm{~mm} / \mathrm{s}$ on the right hemicircumference and $0.8 \mathrm{~mm} / \mathrm{s}$ on the left) [4]. The patient tolerated the procedure well and had no post-procedure pain.

At the 3-month follow-up examination, only a few small islands of Barrett's esophagus remained, and these were treated with the current generation focal cryoballoon ( $\triangleright$ Video $\mathbf{1}$ ). At the 6 -month follow-up check, no Barrett's remained.

Compared with the current generation focal cryoballoon, which freezes smaller areas approximately $2-3 \mathrm{~cm}$ in size, the standard 90 balloon improves upon the prior focal balloon in that a quarter of the esophageal circumference can be treated at a time for a length of up to $3 \mathrm{~cm}$. The next-generation device is physician operated through a foot pedal ( Fig.2). The physician controls the position and placement of the diffuser that releases the cryogen.

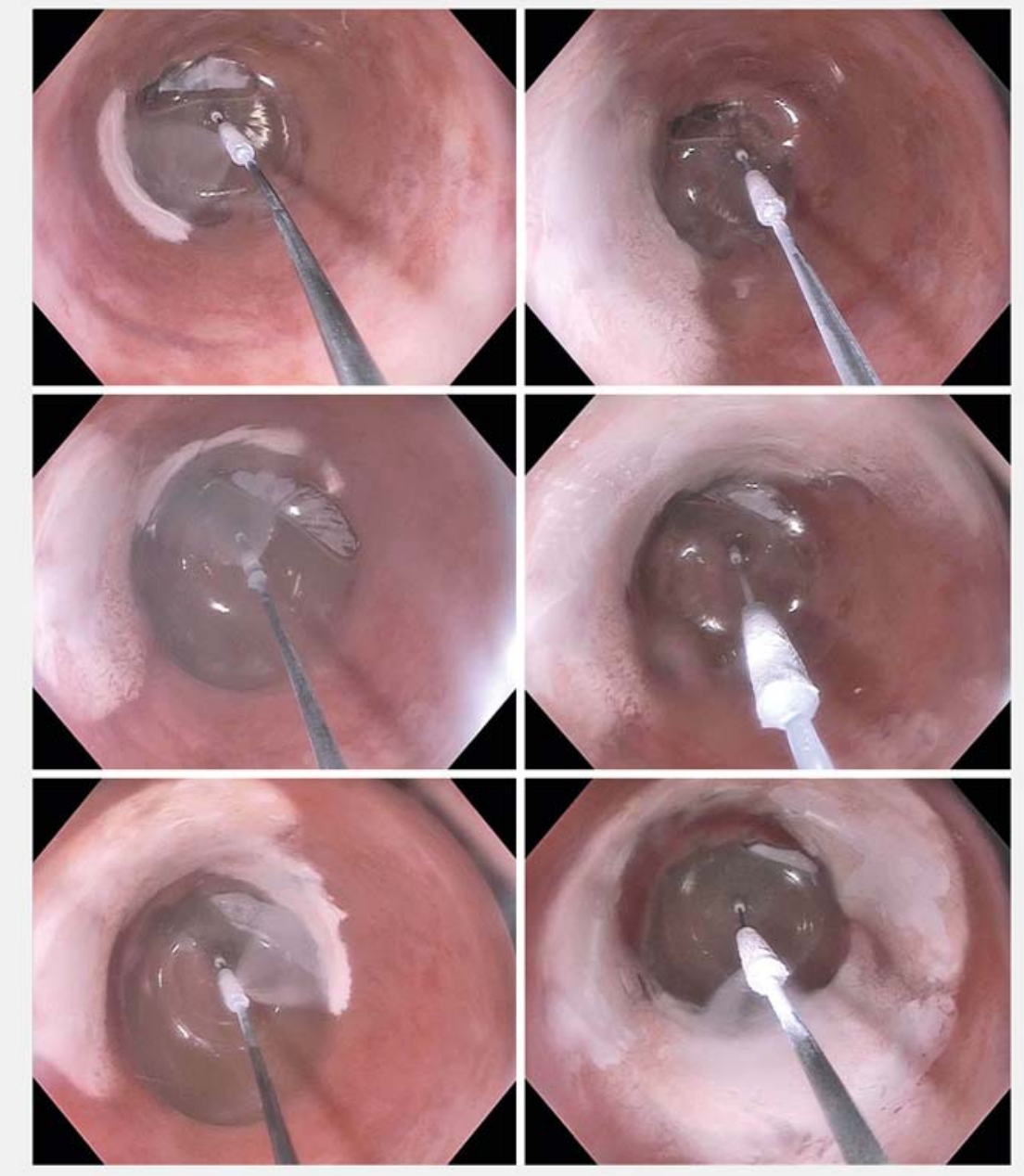

Fig. 1 Treatment of a long segment of Barrett's esophagus with the standard 90 cryoballoon. Each frame represents a different segment being treated within the same $3 \mathrm{~cm}$ of Barrett's esophagus. Moving the diffuser via the foot pedal treats a different quadrant of the Barrett's segment.

This case demonstrates that the nextgeneration cryoballoon ablation system enables successful treatment of wider and longer segments of Barrett's esophagus. Studies are ongoing to determine optimal dosing strategies and technique.

Endoscopy_UCTN_Code_TTT_1AO_2AF

\section{Competing interests}

Drs. Trindade and Canto are consultants for Pentax Medical/C2 Therapeutics. 


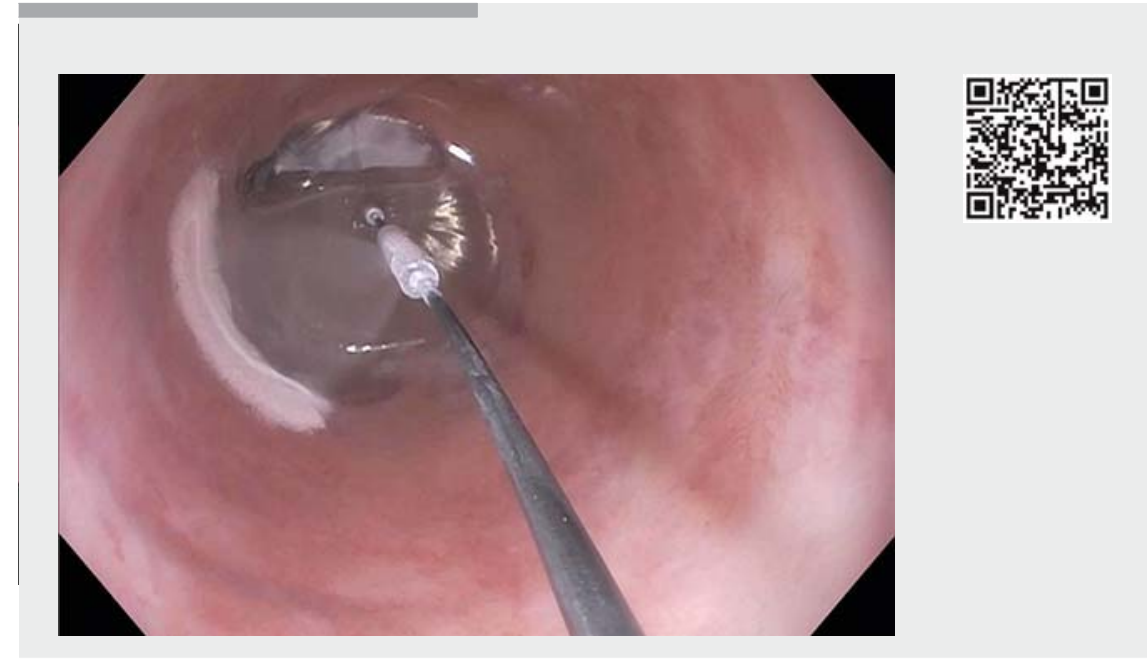

$\nabla$ Video 1 Treatment of a long segment of Barrett's esophagus using the next generation of cryoballoon ablation systems.

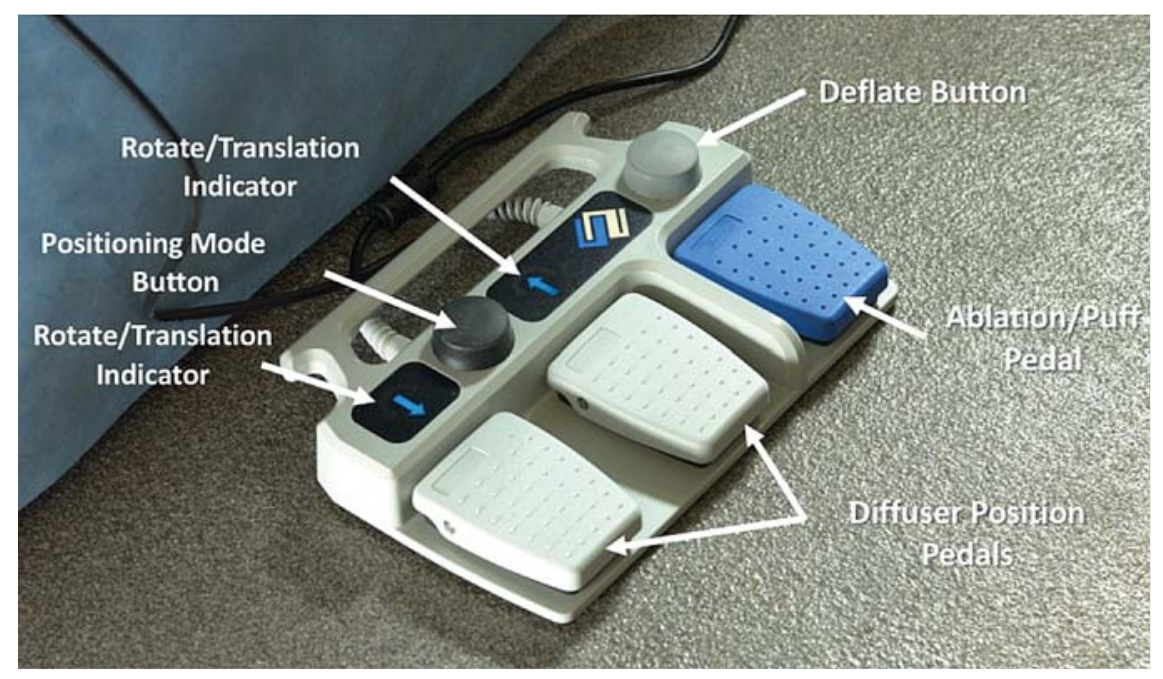

Fig. 2 The foot pedal allows the physician to control the placement of the diffuser to control the location of cryotherapy.

\section{Arvind J. Trindade ${ }^{1}$, Marcia I. Canto ${ }^{2}$}

1 Division of Gastroenterology, Long Island Jewish Medical Center, Zucker School of Medicine at Hofstra/Northwell, Northwell Health System, New Hyde Park, New York, United States

2 Division of Gastroenterology and Hepatology, Johns Hopkins Medical Institutions, Baltimore, Maryland, United States

\section{References}

[1] Canto MI, Shaheen NJ, Almario JA et al. Multifocal nitrous oxide cryoballoon ablation with or without EMR for treatment of neoplastic Barrett's esophagus (with video). Gastrointest Endosc 2018; 88: 438-446

[2] van Munster SN, Overwater A, Haidry R et al. Focal cryoballoon versus radiofrequency ablation of dysplastic Barrett's esophagus: impact on treatment response and postprocedural pain. Gastrointest Endosc 2018; 88: 795-803

[3] Solomon SS, Kothari S, Smallfield GB et al. Liquid nitrogen spray cryotherapy is associated with less postprocedural pain than radiofrequency ablation in Barrett's esophagus: a multicenter prospective study. J Clin Gastroenterol 2018. doi:10.1097| MCG.0000000000000999

[4] Louie BE, Hofstetter W, Triadafilopoulos G et al. Evaluation of a novel cryoballoon swipe ablation system in bench, porcine, and human esophagus models. Dis Esophagus 2018. doi:10.1093/dote/dox155

\section{Bibliography}

DOI https://doi.org/10.1055/a-0824-6058

Published online: 18.1.2019

Endoscopy 2019; 51: E69-E70

(c) Georg Thieme Verlag KG

Stuttgart $\cdot$ New York

ISSN 0013-726X

\section{ENDOSCOPY E-VIDEOS \\ https://eref.thieme.de/e-videos}

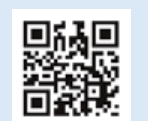

Endoscopy E-Videos is a free access online section, reporting on interesting cases and new techniques in gastroenterological endoscopy. All papers include a high quality video and all contributions are freely accessible online.

This section has its own submission website at

https://mc.manuscriptcentral.com/e-videos 